PLURAL, Revista do Programa de Pós-Graduação em Sociologia da USP, São Paulo, v. 16, n. 2, pp. 75-94, 2009

\title{
Identidades de sucesso: breve reflexão sobre os empresários negros brasileiros
}

\section{Frank Andrews Davies*}

Resumo: Este artigo é uma pequena apresentação das questôes levantadas em minha dissertação de mestrado dedicada aos empresários negros brasileiros. Neste texto são apresentados os métodos e os objetos de investigação e é dada atenção às identidades negras que emergem do grupo de empresários investigado. Constata-se um perfil flexível, porém limitado de representaçóes sobre raça nos discursos dos entrevistados, o que merece ser melhor investigado em vista das recentes aproximaçóes da variável raça ao escopo das relaçóes econômicas. Pretendo trazer contribuições para os debates sobre quem é negro e empresário no Brasil.

Palavras-chave: empresário; empresariado brasileiro; negro; relaçôes raciais; identidade.

\section{Identities of success: a brief reflection on the Brazilian black entrepreneurs}

Abstract: This article is a short presentation of the issues raised in my dissertation devoted to black entrepreneurs in Brazil. In this paper we present the methods and objects of research, and attention is given to black identities that emerge from the group of businessmen investigated. There is a profile of representations of race in the interviewees flexible but limited, which deserves further investigation because of the recent approaches of race to the scope of economic relations. I intend to bring contributions to the debates about who is black and entrepreneur in Brazil Keywords: entrepreneur; Brazilian business; black identity; race relations; identity.

\footnotetext{
* Mestre pelo Programa de Pós-Graduaçáo em Sociologia e Antropologia da Universidade Federal do Rio de
} Janeiro. 
Este artigo se dedica à apresentaçắo de algumas questôes levantadas em minha dissertação sobre os empresários negros brasileiros (DAVIES, 20IO). Para tanto, o interesse é averiguar os elementos identitários que acompanham as ascensōes de alguns desses indivíduos, a partir da conexão entre o agir pessoal e os contextos socioeconômicos. Dessa forma, compreende-se que as combinaçôes entre contingências estruturais e características biográficas são importantes para dar dimensão às "exceçōes à regra" e fundamentar sua existência, apesar das representaçôes sociais e da realidade em si mesma.

A comoção que se propóe sobre esses sujeitos se justifica pela condição racial ${ }^{1}$ e as intercessôes que esse atributo em potencial apresenta no contínuo processo de construção das identidades sociais e práticas empresariais. Nesse sentido, é proposto um intercâmbio entre os debates sobre conduta empresarial, identidade de classe e a questão racial brasileira, tomando como privilégio a discussão sobre as possíveis elaborações do self na atualidade.

A exploração desse tema sob o espectro qualitativo ocorre, então, de duas formas: I) pelo levantamento de fontes de relatos de histórias de vida presentificadas em duas análises sobre o empresariado negro brasileiro, já realizadas pelo sociólogo Jorge Monteiro (200I) e a antropóloga Ângela Figueiredo (2003); 2) pelo pequeno mapeamento de pesquisas em meios de comunicação digital e impressa nos dias atuais.

Foram privilegiados os empresários dos grupos de médio e grande porte, e as justificativas para tanto são posteriormente apresentadas. Por ora, vale dizer que três empresários foram observados de forma mais refinada por este autor, além de outros três recuperados em Monteiro (200I) e mais três na amostra de Figueiredo (2003).

A pesquisa de Jorge Monteiro se concentra nas biografias de nove empresários negros fluminenses, entre os anos de 1987 e 1989, ao passo que Figueiredo (2003) coleta entrevistas com trinta empresários da cidade de Salvador, no ano 200o. Já minha investigaçáo se debruça sobre três empresários negros reconhecidos pela mídia, tendo sido já noticiados em algum momento por conta da condição dupla de negro e empresárioº.

Esses dados sem dúvida não têm representatividade para contemplar todos os empresários e negros brasileiros, mas a intenção aqui é levantar uma série de questôes que envolvem os debates inseridos e, assim, apontar caminhos para investigaçôes mais representativas sobre esse segmento.

Os dias atuais têm se revelado um momento de crise (e, portanto, de renovação) dos cânones da identidade negra ${ }^{3}$. Esta pesquisa pretende contribuir oferecendo uma perspectiva que associa a questão da raça às práticas empresariais, ou seja, com o fito de investigar a consistência da expe-

I Assim definidos como preto e pardo pelos pesquisadores.

2 Vale dizer que a confecção desse estudo aconteceu entre os anos de 2008 e 20Io, o que configura o intervalo médio de uma década entre cada uma das três investigaçóes que ilustram este debate.

3 No ano de 2007, pela primeira vez em muitas décadas, uma pesquisa representativa da populaçáo brasileira detectou o maior número de pessoas autodeclaradas pretas e pardas do que aquelas que se consideraram brancas. Segundo pesquisadores do IPEA, o crescimento dos negros já vinha ocorrendo de forma consistente desde meados da década de I990 e se justifica por uma mudança de postura dos entrevistados, que parecem estar assumindo formas diferentes de se autoclassificarem racionalmente (THEODORO et al., 2008). 
riência racial para a constituição de identidades individuais, tanto no âmbito da empresa - aqui tomada como lócus analítico sociológico privilegiado, verdadeira intersecção entre sociedade e mercado (BERnoux, s/d) - como fora dela, nas questóes que envolvem vida social, preferências pessoais, formas de sociabilidade, etc.

Nesse sentido, são bem-vindas as contribuiçôes teóricas depositadas na Sociologia da Empresa e a chamada Nova Sociologia Econômica. Afinal, o que tal produçáo científica tem afirmado é que a racionalidade instrumental - ou seja, a ação racional com relação a fins de maximização do lucro (WEBER, I99I) - não é uma instância isolada da vida em sociedade. Em outras palavras, a satisfação dos interesses econômicos não acontece de forma alheia aos fatores extraeconômicos que participam das interaçóes indivíduo-sociedade, mas se combinam e se acomodam às questóes culturais, políticas, familiares, associativas, tradicionais e, portanto, identitárias.

A empresa, mais ainda, é um espaço peculiar de observação da interação entre razão instrumental e as outras esferas da vida em sociedade, pois ela é uma unidade organizada de produção que concilia planejamento e hierarquia com negociação e mediação. Ao estudar os empresários, são revelados maiores limites do homo oeconomicus e constatada a possibilidade de participação da identidade racial em uma esfera de açáo importante da vida em sociedade, que envolve produção de trabalho e emprego, circulaçáo de mercadorias e serviços, gerenciamento de pessoal, planejamento produtivo e satisfação de necessidades coletivas.

Dessa forma, mesmo que a presença do negro capitalista represente o anverso do que é percebido majoritariamente na sociedade brasileira, a compreensáo desse segmento pode ser uma instância especial que torna mais claras questôes que são nubladas pelo usual entrelaçamento das percepçóes de "raça" e "classe" sobre a relação entre cultura e racionalidade econômica.

\section{MODOS E FORMAS DOS NEGROS E EMPRESÁRIOS}

A concepção de empresário pode ser arbitrária, ao passo que precisa ser definida metodologicamente. Para isso, sem dúvida, devem ser considerados os caminhos traçados pelos autores que aqui são utilizados como fontes de investigação, ao passo que também importa dimensionar a investigação de maneira consistente, a partir da realidade empírica.

O economista Marcelo Paixão, em um relatório sobre os “empreendedores negros" brasileiros da década de I990, conceitua o termo "empreendedores" a partir da confluência de duas posiçóes na estrutura do mercado de trabalho: os "trabalhadores por conta própria” (ou "autônomos") e os "empregadores". A primeira categoria compreende os profissionais que trabalham sozinhos ou com o suporte de trabalhadores náo remunerados (o que pode incluir a família), enquanto

\footnotetext{
4 No Brasil é clássica a confusão nas representaçóes simbólicas dos negros, relegados aos valores tradicionais e populares que recaem também sobre as classes pobres (SANSONE, 2000). Esse ideário é fundamentado pela desigualdade racial, sedimentada ao longo dos anos (HaSEnbalg, I979; PAIXão, 2003; SABóIA; Sabóia, 2007).
} 
por empregador são agregados os que exercem o papel de patrão de pelo menos um funcionário, com exceção dos trabalhadores domésticos e não remunerados (PAIXÃo, 2003, p. I2).

Ainda que contemplando a amostra a partir da abrangente concepção de "empreendedores", a análise de Paixão (2003) expóe separadamente os resultados obtidos nos dois grupos que formam a categoria, ou seja, autônomos e empregadores. Além disso, extrai dados específicos do grupo dos empregadores com mais de cinco empregados, o que ajuda a melhor definir a posição e o desempenho dos pretos e pardos dentro das empresas mais complexas.

Em minha pesquisa (DAVIES, 20Io) estáo atualizados alguns resultados da análise desse economista, a partir da base de dados da PNAD (Pesquisa Nacional por Amostra de Domicílios) de 2007. Com isso, prolonga-se a investida de Paixão (2003) para os anos próximos, tomando por inteiro os números da década de 1990 (em anos próximos à investigação de Monteiro, de 1987 a 1989) e chegando a 2007, após a pesquisa de Figueiredo (2003) e alcançando praticamente os anos atuais.

Tal preocupação talvez nem seja necessária, tendo em vista que as desigualdades raciais no Brasil apresentam índices incríveis de estabilidade, mesmo com as transformaçóes dos arranjos sociais e econômicos no decorrer desse tempo. Paixão (2003), ao acompanhar os dados referentes à toda a década de 1990, acentua que em um decênio não foram alteradas de modo significativo as posiçóes de negros e brancos no sistema de produção. Dessa maneira, o autor se ateve à exposição dos resultados da PNAD de 1999, por ser a mais recente e a que sintetiza a progressáo tímida que o grupo de pretos e pardos angariou desde o início do período investigado.

Além disso, a atividade empregadora se constituiu como o critério básico definidor de empresário, tal como utilizado por Monteiro (200I) e Figueiredo (2003), o que os aproxima do estudo de Paixão (2003) desses estudos, tendo em vista a proximidade com a definição do objeto de investigação.

No ano de 2007, a participação dos grupos de raça ou cor era próxima à População Economicamente Ativa (PEA) urbana no que se refere aos empregados e aos autônomos, em que os brancos são quase 50\%, os pardos ficam ligeiramente abaixo desse índice, e os pretos náo chegam a IO\% do grupo.

Apesar da "democracia" dos dados em relaçáo à variável racial entre os empregados e autônomos (que juntos somam $84,4 \%$ da PEA urbana), o fato é que subsistem condiçóes segregadoras de participação dos grupos raciais e de gênero em nossa estrutura produtiva. Essas condições se cristalizam com surpreendente durabilidade na história do país, como comprovam os dados.

Por um lado, o trabalho doméstico inflaciona a participaçáo de pretos, pardos e mulheres entre seus ocupados; por outro, os empregadores condensam, por sua vez, homens (7I\%) e brancos $(68,3 \%)$, e apenas 26,I\% deles sáo pardos, e 4,2\% são pretos, ou seja, só 30,3\% dos empregadores são negros, de acordo com a PNAD de 2007.

Essa é uma diferença próxima àquela que envolve o quesito sexo: 71\% dos empregadores são homens, e apenas $29 \%$ são mulheres. 
Tabela 1. Participação dos grupos raciais e de gênero nos segmentos do mercado de trabalho brasileiro em 2007 (\% em linhas).

\begin{tabular}{llclllll}
\hline & \multicolumn{4}{c}{ Grupos raciais } & & \multicolumn{2}{c}{ Gênero } \\
\cline { 2 - 4 } \cline { 7 - 8 } & Brancos & Pretos & Pardos & Negros* & & Mulheres & Homens \\
\hline PEA urbana & $47 \%$ & $9 \%$ & $43 \%$ & $52 \%$ & & $43 \%$ & $57 \%$ \\
Domésticas & $34,7 \%$ & $13,7 \%$ & $40 \%$ & $53,7 \%$ & & $94,6 \%$ & $5,4 \%$ \\
Empregados & $50,4 \%$ & $8,8 \%$ & $50,8 \%$ & $59,6 \%$ & & $39,9 \%$ & $60,1 \%$ \\
Empregador & $68,5 \%$ & $4,2 \%$ & $25,8 \%$ & $30 \%$ & & $29 \%$ & $71 \%$ \\
$\begin{array}{l}\text { Empregadores com 5 ou } \\
+ \text { empregados }\end{array}$ & $77 \%$ & $2,3 \%$ & $18,6 \%$ & $20,9 \%$ & & $26,5 \%$ & $75,3 \%$ \\
\hline
\end{tabular}

Fonte: PNAD (1999; 2007). *A categoria “negro' é a combinação dos grupos pretos e pardos. As porcentagens são referentes às linhas, e não às colunas.

Os números dizem que a representatividade dos negros no grupo empregador ${ }^{5}$ aumenta significativamente nesse intervalo de oito anos: se, em I999, eram 20,9\%, em 2007 eram 30\%.

As atividades que mais concentram empregadores negros em I999 são as de prestação de serviços $(25 \%)$, comércio $(22,2 \%)$ e setor primário $(2 \mathrm{I}, 3 \%)$. Entre os brancos, o comércio é o que concentra mais empregadores $(29,5 \%)$, seguido das atividades de serviço $(22,5 \%)$ e das indústrias em geral (I5,5\%). Tal distribuição setorial pelos grupos raciais de empregadores não sofreu alteraçáo nos oito anos seguintes, o que endossa as interpretaçóes de que a condiçáo que ocupa o branco é privilegiada em relação aos negros, haja vista que são protagonistas dos setores mais dinâmicos do mercado - a indústria e o comércio.

Sobre isso Paixão (2003, p. 9I) corrobora com a perspectiva de que há espaços privilegiados para a atuação dos empregadores negros:

[...] entre os empregadores negros, a importância do setor primário era maior, em quase sete pontos percentuais, ao que ocorria entre os empregadores brancos. Outro setor, cuja diferença relativa entre empregadores brancos e negros era bastante saliente, foi o ramo da construçáo civil. Embora este ramo de atividade seja somente a quarta forma de ocupação entre os empregadores negros, com I2,4\% do contingente, tal percentual era, também, quase sete pontos percentuais maior que o verificado entre os empregadores brancos. Por fim, entre os empregadores negros, ocupação como profissionais liberais e serviços auxiliares da atividade econômica eram as menos relevantes entre esta raça ou grupo de cor, ocupando somente $7 \%$ do total de empregadores negros.

5 O grupo de empregadores é extremamente heterogêneo no que se refere ao porte das empresas, haja vista que contempla do microempresário, responsável pela contratação de um empregado, até aqueles dirigentes das grandes e complexas corporaçóes. 
A concepção de que o negro ocupa um "lugar" na estrutura do mercado de trabalho brasileiro já foi discutida pela socióloga Márcia Lima (200I). Sem adentrar agora nesse debate, vale pontuar que dados nacionais comprovam que a mediana de rendimento mensal dos empregadores brasileiros oscila consideravelmente por conta do critério racial, como pôde ser observado nas análises das PNADs. Em 2007, constata-se que os segmentos preto e pardo dos empregadores ganham, em média, 74\% do que recebem os brancos. De acordo com Paixáo, em I999, ou seja, oito anos antes, a diferença de renda marcava $54 \%$.

Ainda que a análise salarial reflita importantes disparidades raciais, vale salientar que o grupo empregador apresenta índices de maior rendimentos e de menor diferença entre os grupos raciais, quando comparado com outros setores do mercado de trabalho.

Em relaçáo à escolaridade, ao longo da década de 1990, percebe-se a manutenção das diferenças entre brancos e negros no patamar dos 2,5 anos de vantagem aos primeiros. No topo da pirâmide, entretanto, os desafios são mais resistentes. Em 1999, enquanto apenas 8,6\% dos empregadores negros haviam concluído o ensino superior, em 2007, esse número evolui para $\mathrm{I} 2,2 \%$. Os brancos alcançam a mesma aceleração: no primeiro ano os graduados atingem $26, \mathrm{I} \%$ destes e, em 2007, já superam os 30\%.

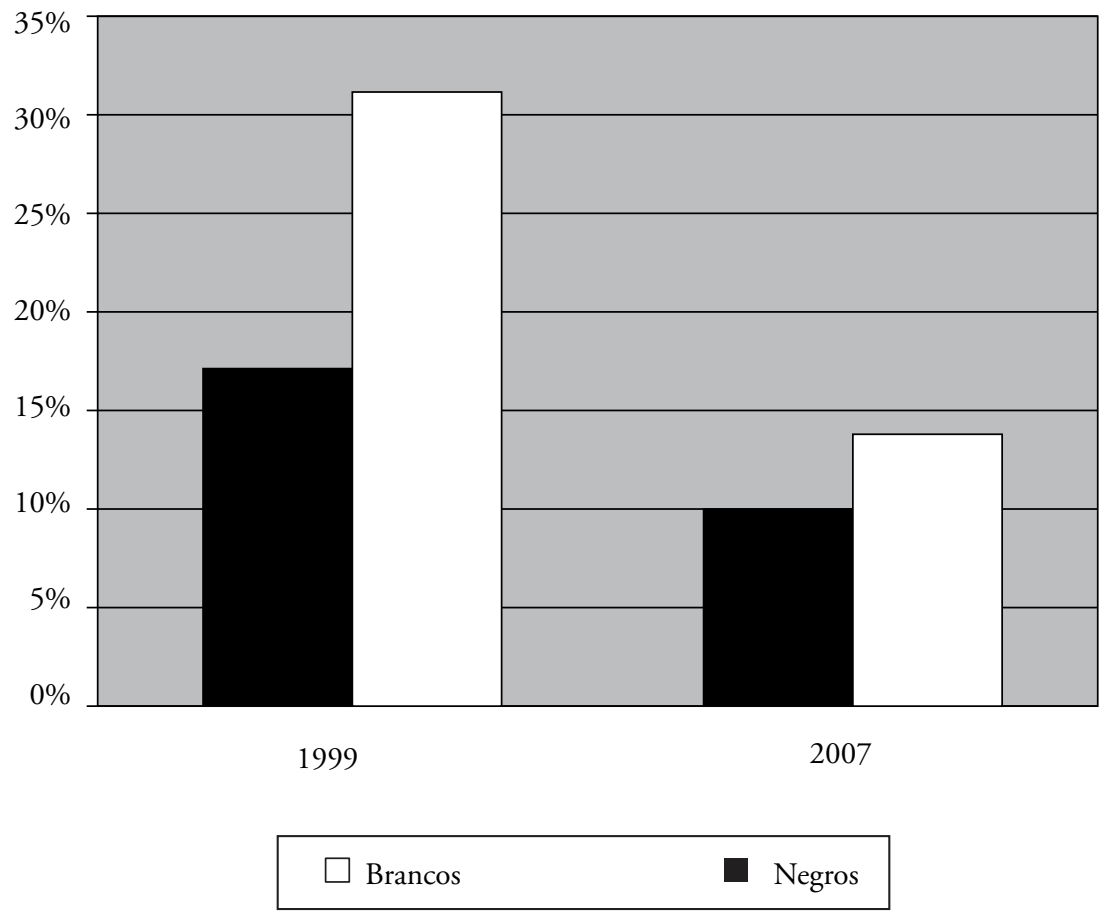

Gráfico 1. Empregadores com cinco ou mais funcionários. As porcentagens se referem ao montante de empregadores dentro dos grupos raciais. Fonte: PNAD (1999; 2007). 


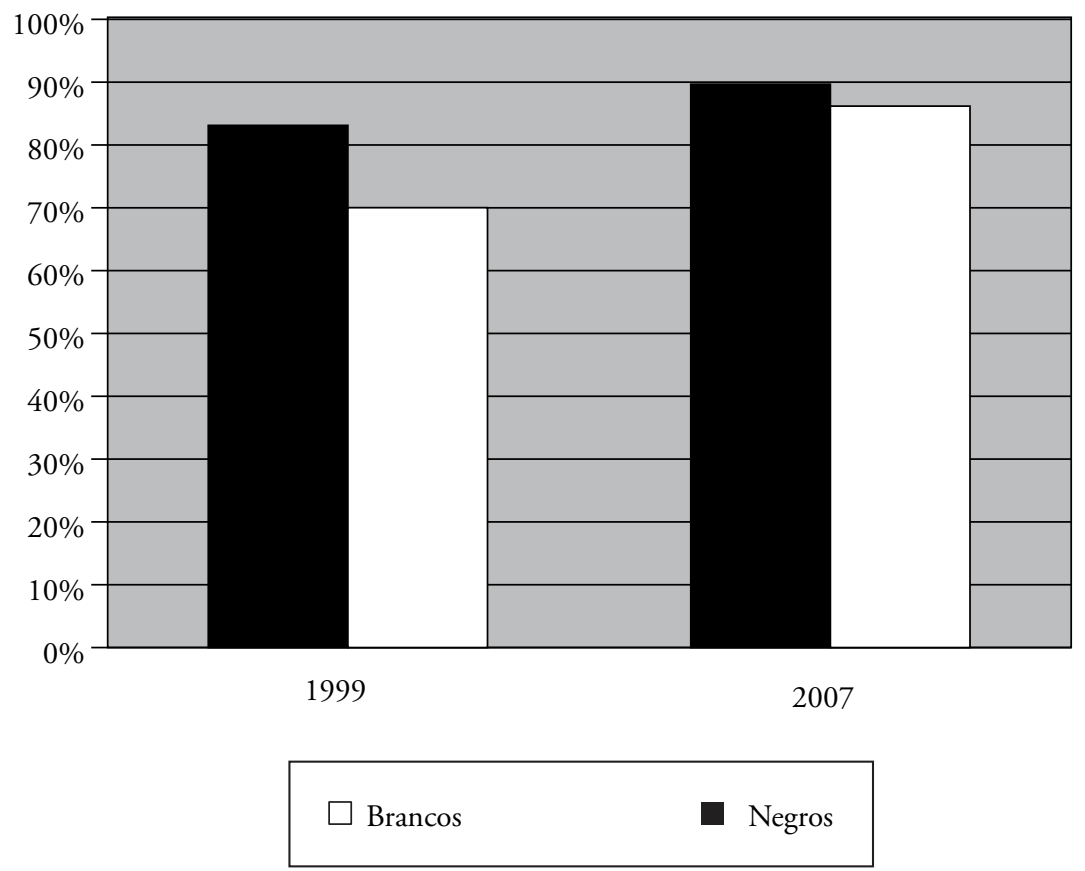

Gráfico 2. Empregadores com menos de cinco funcionários. As porcentagens se referem ao montante de empregadores dentro dos grupos raciais. Fonte: PNAD (1999; 2007).

Marcelo Paixáo (2003) sinaliza que, a partir da natureza amostral da PNAD, poderia ser feito um recorte ótimo de representatividade estatística até os empregadores de cinco ou mais funcionários ${ }^{6}$. É certo que esse recorte está muito aquém da classificação do SEBRAE para as empresas, mas vale para apresentar alguns dados que dimensionam a realidade contemporânea em referência às problemáticas de grupos de trabalho e estruturas burocráticas mais complexas.

Em 1999, apenas 17\% dos empregadores negros possuíam empresas com mais de cinco empregados, ao passo que esse número quase dobrava entre os brancos (31\%). Do outro lado da pirâmide, são $83 \%$ das empresas com até cinco profissionais remunerados comandadas por negros e, entre brancos, 69\%. Em 2007, o número proporcional de empresas com mais de cinco empregados reduz para ambos os grupos, o que pode significar um avanço na sobrevida das micro e pequenas empresas a partir das novas políticas econômicas e fiscais implantadas a partir da segunda metade dos anos 1990. Em 2007, somente 9,9\% dos empregadores negros contavam com mais de meia dezena de subordinados, enquanto isso, entre os brancos, foram $13,7 \%$.

6 A PNAD (2007) revela que esse recorte deflagra um equilíbrio dentro da amostra: $29 \%$ dos casos referem-se aos empregadores que contratavam apenas um funcionário; $19 \%$, com dois; $25 \%$, entre três e cinco; e 26\%, com mais de cinco. 
Sob outra perspectiva, o dados de Paixão (2003, p. II4) deixam evidente a acentuada desigualdade da participação dos grupos raciais no segmento dos empregadores com mais de cinco funcionários. Em I999, registrou-se que, entre eles, 87,7\% eram brancos e, somente, I2,3\% negros. Em 2007, os brancos continuam sendo majoritariamente mais presentes $(77,4 \%)$ do que os negros (20,9\%), os pardos são só I8,6\% do grupo, e os pretos são ínfimos 2,3\%.

Não é intenção aqui comprometer-se com os "porquês" desse progresso substantivo na distribuição de oportunidades e recursos, mas vale citar algumas hipóteses para futuras investidas sobre a questão. São elas:

1) A identificação racial tem passado por um processo de reavaliaçáo na sociedade brasileira, o que explica maiores índices de autodeclaração de pardos - e principalmente de pretos - a partir dos anos 2000 (Theodoro et al., 2008). Como consequência desse fenômeno, há o aumento de negros entre grupos ocupacionais e esferas sociais antes obscurecidas pela vergonha ou "falta de identidade" com o grupo racial em questão.

2) A política econômica e a fiscal para a micro e pequena empresa têm sido repensadas no Brasil desde 1996, com o Programa de Simplificação Tributária para Microempresas. Desde então, propostas como essa têm sido discutidas e implantadas. O resultado é o maior grau de formalização e garantia de direitos desse segmento,

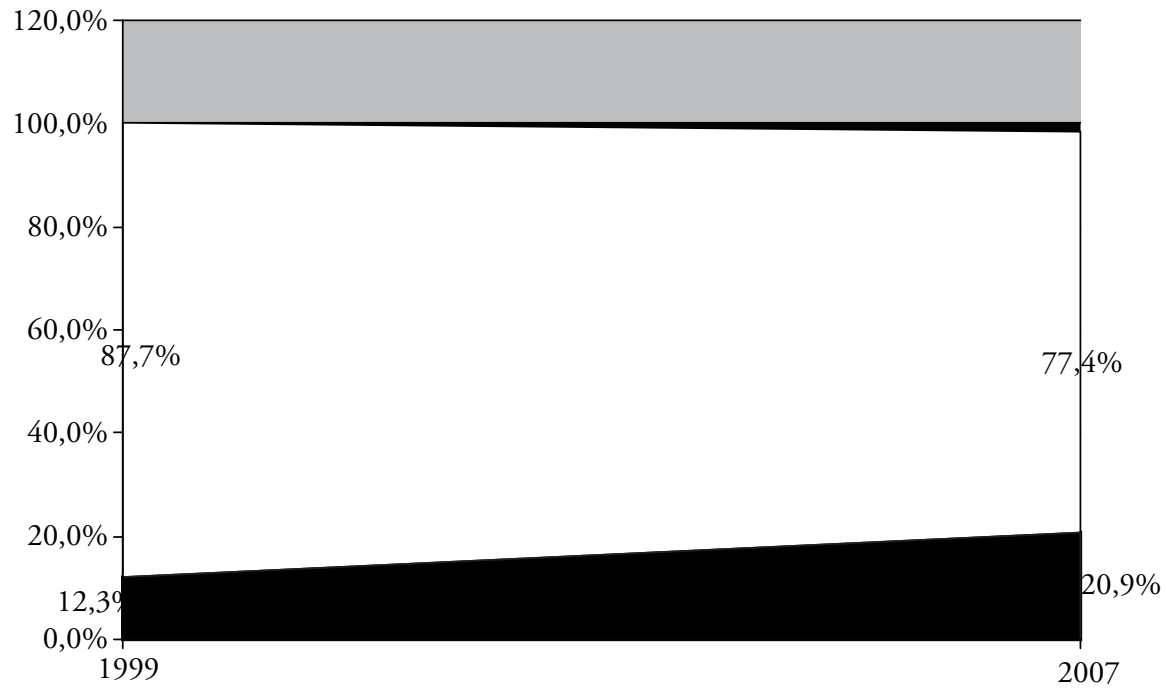

¿Brancos - Negros

Gráfico 3. Composição do grupo de empregadores de cinco ou mais funcionários. Fonte: PnAd (1999; 2007). 
bem como as melhorias que repercutem na maior longevidade e estabilidade das empresas de pequeno porte.

3) A situação política e econômica do país, no plano geral, deixou de lado as propostas neoliberais devotadas ao mercado de importaçáo de produtos. A partir de 2003, com o governo Lula, observa-se estímulo ao mercado interno, criação de novas linhas de empréstimo ao empresariado e estabilidade econômica, táo cara aos empreendimentos mais sensíveis.

Como dito, os motivos podem não se esgotar sob esses três tópicos, mas eles sem dúvida são dados da nova realidade observada a partir desse panorama quantitativo. O que é importante frisar por ora é a continuidade dos índices de desigualdade racial entre os empregadores negros. Em vista disso, será justificada em momento posterior de análise a necessidade do olhar sociológico sobre os negros que ocupam a pirâmide social e econômica brasileira, dados esses inalcançáveis sob o prisma dos dados estatísticos.

\section{ATRIBUTOS E IDENTIDADES DE NOVE EMPRESÁRIOS NEGROS}

Este estudo opta por deixar de lado os empresários de organizaçóes consideradas de micro e pequeno porte, considerando formas "mais autônomas" de gerir as empresas, sem, com isso, desprezar o valor das relaçóes sociais para a realização das práticas econômicas. O recorte em torno das empresas de porte médio - ainda que realizado de forma arbitrária e não táo rígida como transparece a classificaçáo do $\mathrm{EEBRAE}^{7}$ - permite agregar elementos da "personalidade" e da burocracia” (Merton, I966), revelando, de forma mais sofisticada, como (e se) a prática empresarial se combina ao habitus racial (SANSONE, 1995).

Além disso, tal segmento do empresariado comumente realiza, de forma plena, a inserçáo nas classes médias urbanas, o que deixa em maior evidência o debate acerca do pertencimento de classe de alguns negros. Outra questáo que se beneficia do recorte da amostra é a vivência de negros no ethos empresarial, mais amadurecido entre o mundo das empresas médias (CAPPELLIN; GiULIANI, 1999).

Mas quais seriam os pesos atribuídos ao pertencimento racial na narrativa das trajetórias e na constituição das formas próprias de gestão empresarial?

O primeiro dado que se evidencia nas investigaçóes sobre os negros no mercado de trabalho brasileiro é que esse grupo majoritariamente encontra brechas para a ascensão social no conjunto de espaços abertos "a reboque" do fenômeno industrial, ou seja, nos setores de serviços, comércio e construção civil.

$7 \mathrm{Na}$ indústria, as microempresas têm até dezenove empregados e, no setor terciário, são até nove empregados. As pequenas empresas têm até noventa e nove empregados na indústria, sendo que metade disso no comércio e serviços. Esse é um universo de relaçôes marcadas por maior proximidade da unidade de produção e de pessoalizaçáo das relaçóes de trabalho. 
O conjunto de atividades econômicas citadas como lócus negro revela-se como um espaço de maior porosidade à entrada desse segmento na dita economia de mercado. Segundo o pesquisador Roberto Moura (1995, p. 65), foi por meio do pequeno comércio e da prestaçáo de serviços técnicos de rotina que os ex-escravos participaram com maior frequência da economia das cidades, há mais de um século.

Em relaçáo a cada um dos nove empresários reunidos para essa reflexão, vale inicialmente comentar certos aspectos de suas trajetórias.

A partir das fontes, vemos que quatro empresários são do comércio, dois controlam prestadoras de serviços a outras empresas, e outros três são do ramo da construçáo civil. Esses últimos são todos da pesquisa mais antiga, de Monteiro (200I), sendo os demais já advindos das análises dos anos 2000 e 20IO. O recorte do grupo respeita a classificaçáo do SEBRAE em quase todos os casos, excetuando-se um empresário do comércio de Salvador. Ele declarou ter trinta e dois subordinados, porém os demais entrevistados admitiram possuir no mínimo cinquenta empregados (caso de três deles). Outros três afirmaram estar na faixa de cem contratados, ao passo que dois excedem muito esse número, chegando a oitocentos e cinquenta empregados, no caso da proprietária da rede de salóes de beleza.

Sobre as mulheres, além dessa bem-sucedida empresária, conhecida nacionalmente, a pesquisa em Salvador resgata a trajetória de Dadá, ou Alaíde, renomada proprietária de dois restaurantes de comida típica baiana da cidade. Essa pequena investigação comenta que a condição

Tabela 1. Grupo dos nove empresários negros.

\begin{tabular}{llll}
\hline \multicolumn{1}{c}{ Nome } & \multicolumn{1}{c}{ Área } & Cidade sede da empresa & Referência \\
\hline Carlos / "Entrevistado 1" & Construção Civil & Mendes & Monteiro (2001) \\
Clóvis / "Entrevistado 3" & Construção Civil & Nilópolis & Monteiro (2001) \\
Cléber / "Entrevistado 4" & Construção Civil & Rio de Janeiro & Monteiro (2001) \\
Rodrigo & Telefonia & Salvador & Figueiredo (2003) \\
Dadá & Restaurante & Salvador & Figueiredo (2003) \\
Eraldo & Autopeças & Salvador & Figueiredo (2003) \\
Heloísa & Saláo de beleza & Rio de Janeiro & - \\
Mauro & Importação e outros & Vitória & - \\
Humberto & Recursos Humanos & Rio de Janeiro & - \\
\hline
\end{tabular}


de mulher traz para as empresárias negras uma disposiçáo diferente para atuar no mercado: elas comercializam produtos e serviços atrelados ao universo simbólico da "cultura negra", ao passo que nenhum dos homens se realizou profissionalmente sob tal suporte".

As diferenças etárias no grupo não foram grandes, oscilando de trinta e dois a cinquenta e seis anos. A escolaridade foi variada, havendo três com ensino fundamental incompleto, outros três que concluíram o ensino médio e mais três com ensino superior. As faixas de escolaridade náo se conectam diretamente ao porte ou setor das empresas, estando justificadas por questóes de origem, estímulos e oportunidades ao longo do caminho.

Sete dos nove entrevistados relataram a experiência de uma infância difícil, sendo eles de origem bastante pobre. Viviam em meio a muitos irmãos, sob condiçôes precárias, e precisavam colaborar desde cedo trabalhando, prejudicando, assim, os estudos regulares. Somente dois participantes da amostra relataram a condição de herdeiros: um soteropolitano do comércio e um empresário da construçáo civil do Rio de Janeiro. Em ambos os casos, os pais transmitiram seus capitais cultural (o traquejo da prática empresarial), social (a rede de relaçóes que sustentavam os hábitos consolidados) e econômico.

Uma preocupaçáo importante desta pesquisa está em saber como se apresentam esses empresários diante das questôes de identidade de classe e vida associativa. Tal interesse advém do fato de que a condição de negro e membro da classe média se revela náo apenas uma minoria estatística, mas um assunto pouquíssimo explorado pela literatura das relaçôes raciais.

Um dos poucos estudos sobre o grupo, realizado pela antropóloga Ângela Figueiredo (2002) sobre profissionais liberais negros de Salvador, revelou os seguintes dados característicos da "classe média negra" brasileira. São eles:

1) A origem pobre.

2) O recurso ao emprego público, ainda que enquanto artifício subsidiário a outras práticas profissionais.

3) Os frequentes casos de casamento inter-racial ocorridos após a ascensão social, o que sugere ser este um mecanismo de consolidação de status.

4) A não identificação com a "classe média".

5) A pouca relação entre os grupos profissionais e a assunção de uma identidade negra de tipo específico.

6) A presença de negros em determinados ambientes típicos da classe média é considerada suscetível a reaçóes como surpresa e desconfiança.

7) Entretanto, eles costumam reagir a situações discriminatórias, objetivando amenizar conflitos.

8 Este é um dado valioso melhor explorado na dissertação, que sugere que as mulheres são dinamizadoras par excellence do mercado cultural negro no Brasil (SANSONE, 2000), sendo isso talvez uma restrição ou um estigma que recaia sobre elas. Com isso é sugerido que não exista apenas um "lugar" aos negros na estrutura de mercado de trabalho (LIMA, 200I), mas também há um "lugar" às mulheres negras dentro do sistema de gerenciamento produtivo. 
Nossa fonte atesta que estão latentes os signos da "classe média negra" brasileira nos relatos dos empresários. Porém, poucos preferem se definir como membros das camadas médias, mesmo apresentando bens de consumo típicos do grupo. Tal dissociação com relação ao termo náo se refere ao poder aquisitivo, mas aos hábitos e à cultura desse segmento do qual se acham diferenciados. Eraldo deixa isso claro:

Entrevistador: Qual a classe social que você pertence?

Entrevistado: Eu poderia pertence até a classe A ou B... Poderia, mas não tenho necessidade de participar ativamente. Eu posso ter contato, ter alguns amigos, mas não tenho necessidade de ter amigos ricos... Deixa eu ver como vou explicar... Eu até freqüento, mas não tenho o desejo de consumo de me sacrificar para poder freqüentar. Freqüento normalmente, vou a todos os lugares, lugares que se pode gastar muito, que pode gastar pouco sem problemas, não sofro não. Tem muita gente que sofre porque não pode ir a um ambiente, ou que vai gastar; às vezes se sacrificam, mas, eu não tenho essa necessidade (Figueiredo, 2003, p. 199).

O sociólogo Carlos Antonio Costa Ribeiro (2006) pontuou que as trajetórias de mobilidade social criam identidades híbridas quanto às classes sociais. As opiniōes e os hábitos dos indivíduos que experimentam ascensão social são diferentes tanto de seu grupo de origem quanto do segmento a que pertencem.

Tal fato pode explicar a situação dos empresários negros de referência, que, salvo raros casos, declaram não se identificar com os costumes, digamos, conspícuos da classe média branca.

A autoclassificação racial dos entrevistados não apresentou importantes oscilaçốes. Todos se consideram pretos, mulatos e, acima de tudo, negros. Já a negritude, conceito que se reporta às atribuiçóes positivas à condição de "ser negro", não apresenta a mesma uniformidade. Alguns preferem ressaltar a trajetória de mobilidade social em detrimento da raça, enquanto a maior parte só se referiu à raça para retratar episódios discriminatórios.

Pode-se afirmar que existe um perfil flexível, porém limitado de identidades negras assumidas pelo grupo. A relaçáo desses empresários com os objetos da cultura negra (SANSONE, 2000; 2007) não conflui para nenhum sentido específico.

Rodrigo, um dos empresários mais bem-sucedidos do grupo, revela que sua condição de empresário não o eximiu da identificação racial e, principalmente, cultural:

[...] Entấo eu poderia até dizer que eu sou isso, que eu sou aquilo, mas eu gostava e gosto desse detalhe de me considerar preto. [...] Eu sempre fui contra aquilo que as pessoas queriam estereotipar ou colocar como parâmetro, entâo eu sempre chegava com aquela coisa e dizia em determinados momentos da vida; as pessoas me achavam preto, e eu várias vezes já tive perguntas assim, em roda de amigos, porque eu, quando empresário, tive sucesso, eu abracei a causa negra, e sempre tudo aquilo que envolvia negro eu ia e 
várias vezes me perguntei: "Você se acha negro?", e eu perguntava sempre: "O que você acha que eu sou?", "Ah, mas você não é negro", eu me acho negro e sou negro e minha cultura é negra, eu sou negro e sempre vi desse lado. Então eu tive dificuldades assim, vamos dizer, que as pessoas queriam me estereotipar como qualquer outra coisa, menos negro (FIgUeIREDO, 2002, p. I66).

Como pontuou Figueiredo (2002), a identidade racial não deve ser tomada como um espaço de valores culturais, tão somente. Essa concepção essencialista do conceito de identidade inegavelmente conduz-nos a interpretaçóes sociológicas que apontam que ser negro é também ser pobre e, dessa forma, conclui que o negro de classe média é um trânsfuga que deseja, acima de tudo, embranquecer socialmente (AzEvedo, 1996).

Ao compreender a cultura como um sistema de símbolos que indicam os contornos dos grupos sociais, percebe-se que os símbolos negros participam somente de determinados aspectos da vida dos negros e empresários. Alguns expõem hábitos "negros” em eventos públicos, enquanto outros os reservam para a vida privada. Grande parte da assimilaçáo de costumes atribuídos aos negros é fruto da incorporação dos símbolos a partir de um novo estilo de vida (FIGUEIREdo, 2002, p. IIo). Entretanto, como fica claro para esta pesquisa, as construçóes identitárias não estão sujeitas a regras restritas, mas às condicionantes das trajetórias biográficas que conferem pesos diferentes às questôes raciais entre esses sujeitos.

Figueiredo (2002, p. 90) percebeu que, entre os profissionais liberais negros de Salvador, existem diferentes formas de "ser negro", sendo que a maioria da amostra compartilha os aspectos culturais mais presentes na mídia e no cotidiano da cidade de Salvador, como a música e a dança. Alguns somente estavam integrados aos aspectos religiosos da cultura negra. A identidade política reivindicativa também era restrita a uma parcela da amostra.

Por conta da fluidez de possibilidades, a autora acenou para a necessidade de categorizar tipos possíveis de identidade racial. Acompanhando tais consideraçóes, podemos assim definir as possíveis identidades negras:

1) Os radicais são "aqueles que priorizam a raça em seu discurso e interpretam as experiências de vida e a realidade em função da desigualdade e do preconceito racial" (Figueiredo, 2002, p. 91). Costuma ser um recurso retórico para o grupo fazer comparaçóes e referências à experiência de luta dos negros norte-americanos, que, na maior parte das vezes, acena para soluçóes revolucionárias (ou ao menos de transformaçóes mais profundas) em nosso modelo de relaçóes raciais.

2) Já os alternativos são, nas palavras da autora:

[...] aqueles que reconhecem o preconceito e a desigualdade racial na sociedade, mas que se relacionam de uma maneira individual com o problema. A cor ou a raça são vistas como critérios importantes na obtenção de privilégios e vantagens, mas eles acreditam que, com grande esforço e investimento pessoal, essa desvantagem tende a ser minimizada. A ênfase é dada ao indivíduo, que deve se esforçar para superar as barreiras impostas pelo preconceito de cor. Os entrevistados afirmam as suas características fenotípicas e 
sua ascendência negra, mas o fazem de modo individual, menos contestatório e político (Figueiredo, 2002, p. 92).

Nesse sentido, os alternativos se diferenciam por, ao mesmo tempo em que confirmam os efeitos negativos embutidos na marca da negritude, acreditam que a reação deve ocorrer principalmente por esforços pessoais.

3) Os assertivos, por sua vez, são os que deixam em evidência a cidadania e a identidade nacional em um esforço de caracterizar suas identidades. Apesar disso, não negam o racismo - ainda que náo acreditem que situaçóes de preconceito racial aconteçam com eles.

Dessa forma, podem ser caracterizados pela importância reduzida que dão à categoria negro no plano discursivo. Vale ilustrar com a fala de Carmen, uma médica residente de Salvador de cinquenta e dois anos:

As meninas aqui em casa sempre foram educadas e informadas de que elas são pessoas, independente de cor e situação socioeconômica, elas são cidadãs, e eu sempre mostrei que elas tinham direitos, deveres, evidentemente, mas que deveriam lutar para que fossem respeitadas como cidadãs (FigueIredo, 2002, p. 93).

4) Os democráticos, por fim, são "[...] aqueles em que a cor está completamente ausente do discurso e que, quando indagados sobre o assunto, afirmam em primeira instância que o que importa são as pessoas e não a cor" (Figueiredo, 2002, p. 93). Esse modelo de discurso pode ser exemplificado pela fala de Carlos, empresário da construção civil de Mendes:

Discriminação? Eu acredito que não há não, se houver é muito pouca coisa. Os negros hoje estão muito mais inteligentes, estão estudiosos [...] discriminação não há mais aqui não [...]. Esta discriminação é nossa mesmo, acho que o próprio negro fica sem coragem de tentar, achando que a cor dele não vai dar... Estas coisas todas. Mas está partindo da gente mesmo (MonTEIro, 200I, p. I59).

Essas categorias de identidades raciais sáo, de certa forma, reconhecidas pelos entrevistados ao se referirem a si mesmos e aos outros. Além disso, tal tipologia permite localizar as representações discursivas que atribuem valor à filiação racial. Invariavelmente, essa problemática se envolve na relaçáo intrínseca dos sujeitos aos ideais de "democracia racial". Dito de outra forma, a categorizaçáo organiza as falas dos pretos e pardos brasileiros em referência à perspectiva generalizada de que vivemos em uma sociedade de relaçôes raciais harmoniosas (GUIMARÃES, 2002).

$\mathrm{Na}$ pesquisa com os profissionais liberais, foi percebido que grande parte do grupo estava alinhada às duas categorias intermediárias, sendo que metade da amostra tinha o perfil alter- 
nativo, e outros $30 \%$ estavam afinados à identidade assertiva. Por fim estavam os radicais e os democráticos, ambos com $20 \%$ do grupo.

No presente levantamento, é curioso notar que estão espalhados em três dessas categorias, enquanto nenhum dos nove empresários manifestou a identidade radical em seu discurso. Ao que fica sugerido, quando próximo do topo da pirâmide social, os negros costumam elaborar identidades alternativas ou assertivas. Isso faz sentido quando ainda se soma o fato de que a conduta empresarial exige ao extremo a capacidade de diálogo desses agentes, e, portanto, o discurso racialista representaria por si só entraves a tal objetivo.

No universo de nove empresários, somente dois expuseram argumentos de uma identidade democrática. É o caso de Humberto, empresário de recursos humanos do Rio de Janeiro, e de Carlos, empresário da construção civil há pouco citado. Os sete demais oscilam entre percepçôes alternativas e assertivas, ou seja, que concordam quanto ao preconceito e ao racismo na sociedade, mas divergem quanto à sua importância na confecçáo das trajetórias sociais. Nesse sentido, acreditam que, se há obstáculo em vista da condiçáo racial, este pode ser contornado por meio de esforços pessoais.

As identidades autoatribuídas por esses empresários parecem associadas a uma pluralidade de fatores que esta pesquisa só alcança a título de sugestão.

Um deles é o fato de que a preponderância desse perfil identitário resguarda proximidades com o discurso do self-made man, recorrentemente incrustado na "ideologia do sucesso" (MarTins, I967, p. 59). Tal retórica pontua os processos de ascensáo social, tendo por base os esforços persistentes de pessoas que, hoje, são recompensadas com a prosperidade de seus investimentos. É uma narrativa biográfica que se assemelha a muitos discursos do empresariado brasileiro, principalmente entre os fundadores das empresas de porte médio, grupo majoritário desta investigação.

Esse discurso logra a força de vontade e a motivaçáo pessoal como verdadeiros motores propulsores da ascensáo social, deslegitimando, assim, as reivindicaçóes por igualdades de oportunidades entre os grupos sociais diferenciados. Diante disso, fica a pergunta: se, de acordo com esse discurso, é possível "crescer na vida" vindo de baixo, porque seus adeptos deveriam se ancorar em atributos que, de certa forma, funcionam como empecilho para esse projeto? A raça, nesse sentido, torna essa trajetória "estranha" para os negros, que, assim, se apropriam de identidades raciais quase alheias aos valores da negritude.

Outros fatores contribuem para essas configuraçóes, sendo um deles a origem das empresas e a autonomia do empresário no processo de consolidação de status. Em relação à inserção nas redes sociais e na vida associativa, é possível constatar que os empresários estão integrados a uma série de grupos, participando principalmente de redes privilegiadas de contatos dentro do mundo dos negócios.

9 Um dos dois empresários de identidade democrática parecia assim ser em razão do apadrinhamento que o tutelou ou ainda tutela, caso de um ex-patrão judeu que lhe deu a chance para se desenvolver e abrir sua própria empresa de recursos humanos na cidade do Rio de Janeiro (Humberto). 
As associações de classe são enfaticamente citadas nos relatos dos empresários democráticos, especificamente referidas ao Rotary. O Rotary Clube é uma organização internacional de tradiçấo que congrega hoje mais de 1,2 milhão de sócios no mundo, sendo cinquenta e três mil no Brasil. O objetivo da instituição é fomentar uma rede extensa de contatos entre profissionais de diferentes matizes, estabelecendo laços de solidariedade entre eles e em relação às suas comunidades. Por certo o prestígio é um dos signos distintivos que os rotarianos perseguem com sua filiação, assim como estimulam a liderança no grupo. Evidentemente, o rigor necessário para filiação conduz a uma composição racial predominantemente branca.

Nesse sentido, há de se observar que as identidades menos atreladas aos símbolos negros são as mais porosas ao habitus de classe. Ou seja, o discurso pouco afeito aos argumentos da negritude tem sido preenchido por identificaçōes em outros aspectos, ao que parece, mais interessados no convívio e sob os valores do segmento branco, médio e empresarial brasileiro. Vale ressaltar, entretanto, que a maioria dos empresários observados gesta um discurso que mistura essas duas vertentes, a da raça e a do pertencimento a um grupo socialmente muito prestigiado, assim transitando entre mundos que parecem distantes.

\section{CONSIDERAÇÕES}

Quando os nove empresários apropriados para esta reflexáo são comparados com empreendedores que atuam em contextos de microempresas, tendo em vista as categorias identitárias elaboradas por Figueiredo (2002), observa-se que não existem casos de identidade radical entre os empresários de grupos de médio e grande porte, ao passo que os micro e pequenos empreendedores contam com alguns exemplos desse tipo, assim como outras pesquisas comentam ser em relação aos profissionais liberais (FIgUeIredo, 2002; SoARes, 2004; SouZA, 2008).

É curioso notar que, em estruturas burocráticas mais complexas e que envolvem maior poder de comando, as identidades negras se revestem de argumentos que privilegiam menos a experiência racial. Apesar de as situaçôes discriminatórias já terem sido vividas e testemunhadas, esses indivíduos náo se apropriam de maneira primordial da condição de negro para o exercício demandado pela empresa.

Ao mesmo tempo em que assim se caracteriza a identidade negra entre os empresários, a cultura racial e seus símbolos são referência para determinadas açôes e representaçôes, ainda que na maior parte das vezes dissociada das práticas econômicas e do ethos empresarial. Conforme se tem constatado, a identidade negra se acomoda às estruturas de relaçóes sociais muito particulares, o que faz com que ela apresente uma pluralidade vasta de possibilidades de se realizar, que em natureza, se distinguem da clássica dicotomia entre o modelo brasileiro/ibérico e o norte-américo/ anglo-saxão (FrY, I992; GuIMARÃES, 2002).

A configuração da identidade negra no empresariado brasileiro pode ser atribuída a alguns fatores, mas somente como hipótese são feitas essas sugestóes: 
1) A cultura empresarial, mais do que outros mundos, necessita de diálogo e conciliação entre os agentes que circunscreve. Como muitos estudos da Sociologia econômica vêm apontando, a formação de redes sociais é um privilégio para as práticas econômicas. O empresário, senhor da produção e da aquisição do lucro, náo pode negligenciar as oportunidades de parceria e negócios. A leitura de Mark Granovetter e Patrick McGuire (1998) é um dos exemplos que ilustram a pertinência das relaçóes sociais em curso para desenvolvimento das indústrias e dos segmentos de produção.

2) No caso dos negros, a falta de tradição familiar e de pares dentro do grupo empresarial pode condicionar os empresários das organizaçóes de médio e grande porte a um arranjo identitário de tipo mais conciliatório, evitando, assim, o isolamento e o insucesso das empresas.

3) A situaçáo de fragilidade que demarca as origens sociais desse segmento os leva invariavelmente a valorizar ainda mais o peso do capital social (ForTEs, 2000) para o sucesso empresarial. Nesse sentido, náo somente os herdeiros revelam esse peso, mas os fundadores comentam a importância dos laços de afinidade para abertura e continuidade das empresas. Nesse sentido, adotar posicionamentos mais radicais traz desvantagens ao êxito econômico pretendido.

4) Em outro sentido, o ideário de "democracia racial", do qual os negros de classe média parecem ser o marco de sua concretização no plano social (AzEvedo, 1996), talvez contribua fomentando as representaçôes e influenciando-os diante das escolhas que fazem nos processos decisórios e identitários. Assim, de certa forma, ao menos uma parcela desses negros estaria comprometida ideologicamente com a concepçáo das indiferenças entre as raças no Brasil.

O despertar do século XXI tem apresentado novas questôes que apenas foram pinceladas neste texto. A reordenaçáo dos princípios vigentes de justiça social e reparação, suscitada a partir da implantaçáo de políticas afirmativas, pode representar um novo cenário para o agir do empresariado negro e a constituição de suas subjetividades.

Seja como for, os empresários aqui investigados não provieram das preocupaçóes mais recentes, como as açóes afirmativas. Apesar disso, alguns já dialogam com essa lógica para a realizaçăo de suas práticas empresariais no cenário contemporâneo.

É preciso compreender melhor essa dinâmica, entendendo que a variável raça tende a se envolver cada vez mais no mundo da empresa, a partir do privilégio das práticas econômicas. Essa dinâmica é acessada pelas redes sociais, chave propulsora do desenvolvimento de negócios e conquista de novos mercados. Entretanto, esse é um fluxo recente que, como vimos, entra em confronto com outras visóes e realidades sobre a identidade negra no empresariado brasileiro.

As complexidades do jogo das práticas e das representaçóes sociais tornam ainda mais interessante essa discussão. É patente observar que esse debate não se esgota aqui. Não foi de longe a intençáo desta pesquisa, ao contrário, pretendeu-se aqui, esboçar meramente as linhas iniciais de um debate de grande fôlego sociológico. 


\section{REFERÊNCIAS BIBLIOGRÁFICAS}

Azevedo, Tales de. As elites de cor numa cidade brasileira: um estudo de ascensão social, classes sociais e grupos de prestígio. Salvador: Edufba, 1996.

Bernoux, Pierre. A Sociologia das empresas. Porto, Portugal: Ed. Rés., s/d.

Cappellin, Paola; Giuliani, Gian Mario. Os herdeiros: estudo de caso das empresas de porte médio da região serrana do estado do Rio de Janeiro. In: Kirschner, A. M.; Gomes, E. R (Org.). Empresa, empresários e sociedade. Rio de Janeiro: Sette Letras, 1999. pp. 278-300.

Costa Ribeiro, Carlos Antonio. Mobilidade social passada e futura: correlaçóes com opinióes políticas, percepçóes sobre conflito e sobre chances de vida. In: SCALon, C. (Org.). Imagens da desigualdade. Belo Horizonte: Ed. UFMG, 2006.

Davies, Frank. Negros empresários, empresários negros: reflexóes sobre identidades e racionalidade no Brasil. 2010. Dissertaçáo (Mestrado em Sociologia) - Universidade Federal do Rio de Janeiro, Rio de Janeiro, 2010.

Figueiredo, Angela. Novas elites de cor - Estudo sobre os profissionais liberais negros de Salvador. São Paulo: Editora Annablume, 2002.

. A classe média negra não vai ao paraíso: trajetórias, perfis e negritude entre os empresários negros. 2003. Tese (Doutorado em Sociologia) - Iuperj, Rio de Janeiro, 2003.

Fortes, Alejandro. Capital social: origens e aplicaçóes na Sociologia contemporânea. Sociologia, problemas e práticas, n. 33, 2000.

FrY, Peter. Politicamente correto num lugar, incorreto noutro? Estudos Afro-Asiáticos, Rio de Janeiro, v. 23, 1992.

Granovetter, Mark; Mcguire, Patrick. The making of an industry: electricity in the United States. In: Callon, M. (Org.). The laws of the markets. Oxford: Blackwell, 1998. Disponível em: <http://www.stanfordmedicalresearch.com/dept/soc/people/mgranovetter/documents/ granlawsmarkets.pdf>.

Guimarāes, Antonio Sérgio. Raça, classe e democracia. São Paulo: Editora 34, 2002.

Hasenbalg, Carlos. Discriminaçẫo e desigualdades raciais no Brasil. Rio de Janeiro: Graal, 1979.

Lima, Márcia. Serviço de "branco" e serviço de "preto". Um estudo sobre "cor" e trabalho no Brasil urbano. 2001. Tese (Doutorado em Sociologia e Antropologia) - UFRJ, Rio de Janeiro, 2001.

Martins, José de Souza. Empresário e empresa na biografia do Conde Matarazzo. 1. ed. Rio de Janeiro: Instituto de Ciências Sociais - UFRJ, 1967. v. 1. 
Merton, Robert. Estrutura burocrática e personalidade. In: Campos, Eduardo (Org.). Sociologia da burocracia. Rio de Janeiro: Zahar, 1966.

Monteiro, Jorge. O empresário negro: histórias de vida e trajetórias de sucesso em busca da afirmação social. Rio de Janeiro: OR Produtor Independente, 2001.

Moura, Roberto. Tia Ciata e a pequena África no Rio de Janeiro. Rio de Janeiro: Biblioteca Carioca, 1995.

PaIXÃo, Marcelo. Destino manifesto: estudo sobre o perfil familiar, social e econômico dos empreendedores/as afrobrasileiros/as dos anos 1990. 2003. Relatório final de pesquisa (Projeto BRA/01/013) - Programa das Naçóes Unidas para o Desenvolvimento (Pnud), Rio de Janeiro, 2003.

Pesquisa Nacional por Amostra de Domicílios (PNAD). Microdados. 1999. Disponível em: <http:// www.ibge.gov.br/home/estatistica/populacao/trabalhoerendimento/pnad2009/microdados. shtm>. Acesso em: 10/08/2009.

. Microdados. 2007. Disponível em: <http://www.ibge.gov.br/home/estatistica/populacao/ trabalhoerendimento/pnad2007/microdados.shtm>. Acesso em: 10/08/2009.

Saboia, A.; Saboia, J. Brancos, pretos e pardos no mercado de trabalho no Brasil. Um estudo sobre desigualdades. 2007. Disponível em: <www.ie.ufrj.br/aparte/pdfs /artigocoranaesaboiavf_1_. pdf 23/10/2009>.

SAnsone, L. O local e o global na afro-Bahia contemporânea. Revista Brasileira de Ciências Sociais, v. 10, n. 29, 1995.

. Os OBJETOS DA IDENTIDADE NEGRA: CONSUMO, mercantilização, globalização e a criação de culturas negras no Brasil. Mana, v. 1, n. 6, 2000.

. Negritude Sem etnicidade. Rio de Janeiro; Salvador: Ed. Pallas; EdUfBA, 2007.

Soares, Reinaldo. Negros de classe média em São Paulo: estilo de vida e identidade negra. 2004. Tese (Doutorado em Antropologia) - Universidade de São Paulo, São Paulo, 2004,

Souza, Gabriel. Os negros de camadas médias no Rio de Janeiro: um estudo sobre identidades sociais. 2004. Dissertação (Mestrado em Ciências Sociais) - Universidade Estadual do Rio de Janeiro, Rio de Janeiro, 2008.

Theodoro, M. et al. As politicas públicas e a desigualdade racial no Brasil 120 anos após a Abolição. Brasília: IpEA, 2008.

Weber, Max. Conceitos sociológicos fundamentais. In: Economia e sociedade. Brasília: Ed. UnB, 1991. v. 1. 